\title{
Analisa Sebaran Kandungan Fosfat di Muara Sungai Bodri, Kendal Jawa Tengah Ameylia Ayu Puspitasari ${ }^{1}$, Muhammad Zainuri ${ }^{1}$, Heryoso Setiyono $^{1}$,
Sri Yulina Wulandari ${ }^{1}$ dan Lilik Maslukah $^{1}$
}

${ }^{1}$ Departemen Oseanografi, Jurusan Ilmu Kelautan, Fakultas Perikanan dan Ilmu Kelautan, Universitas Diponegoro Jl. Prof. H. Soedarto, SH, Tembalang Semarang. 50275 Telp/Fax (024) 7474698

*Email: ameyliaayupuspita@ student.undip.ac.id

\begin{abstract}
Abstrak
Kendal adalah salah satu daerah di Jawa Tengah yang merupakan daerah yang cukup padat penduduk dan memiliki aktifitas industri dan kegiatan manusia yang cukup tingi pula. Keadaan tersebut menyebabkan adanya degradasi limbah yang berakibat pada peningkatan bahan organik di wilayah pesisir dan pantai yang dibawa dari daratan melalui sungai dan mengarah ke muara. Muara Sungai Bodri merupakan sungai dengan masukan limbah organik yang berasal dari kegiatan pertanian, pertambakan dan perikanan. Dengan masuknya limbah organik ke perairan, struktur komunitas plankton dan kualitas perairan akan mengalami perubahan sesuai dengan pengaruh cuaca dan pasang surut. Keadaan tersebut juga dapat mengakibatkan kenaikan kandungan nutrien terutama fosfat, fosfat adalah salah satu unsur yang mempengaruhi kesuburan perairan. Tujuan dari penelitian ini adalah untuk mengetahui kandungan serta pola sebaran fosfat di Muara Sungai Bodri. Penelitian di Muara Sungai Bodri, Kendal dilaksanakan pada Tanggal 30 September 2020. Penentuan lokasi titik penelitian menggunakan metode purposive sampling di 9 titik yang berbeda. Analisa kandungan fosfat di Muara sungai Bodri memiliki rata-rata konsentrasi sebesar 0,27 $\mu \mathrm{M}$. Persebaran konsentrasi fosfat menunjukan adanya hubungan linier dengan kecepatan dan arah arus di wilayah tersebut. Semakin besar kecepatan arus maka nilai konsentrasi fosfat juga semakin besar, begitupula dengan arah arus, bahwa konsentrasi fosfat semakin tinggi di titik yang dilalui massa air yang dipengaruhi arus dari darat di wilayah tersebut yaitu menuju timur laut.
\end{abstract}

Kata kunci : $\quad$ Fosfat, Persebaran Fosfat, Arus Pasang Surut, Sungai Bodri, Perairan Kendal

\begin{abstract}
Kendal is one of the region in Central Java that is one of the densely populated region and has high industrials and humans activities as well. This situation causes waste degradation which results that increase organic matter in the coastal and coastal areas which is carry from the mainland through rivers and towards the estuary. The mouth of the estuary Bodry is a river with organic waste input from agriculture, aquaculture and fisheries activities. By the entry of the waste into the water, the structure plankton community and quality of the water will change by the influence of weather and tides. This situation can also lead to increase nutrients especially in phosphate. Phosphate is one of the elements that caused the fertility of water. The aim of this study is to know the content and the distribution of formula of phosphate in the Bodry river estuary. Researcher done this research on September 30, 2020. The researcher determinates the location of the points of research by using purposive sampling method at 9 different points. Analysis of the phosphate content in the mouth of Bodri river estuary had a concentrate average between $0.27 \mu M$. The distribution of the concentrate of phosphate showed there are correlations linear by the speed and directions of the flew in that area. The greater the current velocity, the greater the value of the phosphate concentration. As well as the direction of the current, that the higher the phosphate concentration at the point where the water mass that carry by current flew in the region, namely towards the northeast.
\end{abstract}

Keywords: $\quad$ Phosphate, Phosphate Distribution, Tidal Flow, Bodri River, Waters Kendal

\section{PENDAHULUAN}

Sungai Bodri merupakan salah satu sungai di Provinsi Jawa Tengah, Indonesia, dan merupakan sungai terbesar di Kabupaten Kendal. Sungai Bodri mengalir dari selatan ke utara. Muara Sungai Bodri dengan sempadan mangrove serta sebagian wilayahnya telah dikonversi menjadi pemukiman penduduk, 
industri, pertambakan dan Tempat pelelangan ikan. Terutama di sekitar muara sungai Bodri yang telah dibangun pabrik Industri. Kegiatan masyarat di sekitar sungai Bodri akan mempengaruhi kondisi perairan. Keadaan tersebut juga dapat mengakibatkan kenaikan kandungan nutrient salah satunya fosfat (P). Fosfat adalah salah satu unsur yang mempengaruhi kesuburan perairan. Jika kandungan tersebut melibihi ambang batas maka akan terjadi eutrifikasi yang bersifat toxic atau racun. Eutrifikasi adalah pengayaan zat hara, yang ditandai dengan terjadinya blooming fitoplankton menyebabkan kematian berbagai jenis biota laut (Patty, dkk. 2015). Falkowski (2003), menyatakan bahwa keberadaan nutrien termasuk fosfat dan nitrat, terkait erat dengan siklus biogeokimia, yang pada akhirnya berujung pada proses produktivitas perairan. Bahan-bahan organik dan anorganik yang terdapat di muara sungai sebagian diendapkan, terlarut dan terbawa oleh arus ke laut. Salah satu proses yang mempengaruhi konsentrasi bahan-bahan organik dan anorganik pada muara sungai adalah proses biologi (Cervetto, 2002). Proses biologi dalam air dapat dikategorikan menjadi 2 (dua) bagian yaitu proses respirasi dan proses fotosintesis

Maslukah et. al., (2019) menyatakan bahwa unsur nitrat dan fosfat dalam badan air sungai hingga ke muara mempunyai kandungan yang dinamis, terkait dengan berbagai parameter fisika, kimia dan biologi lingkungan. Menurut Sutamihardja (1992), kualitas perairan dapat menurun, karena adanya kegiatan kegiatan masyarakat yang berpotensi menghasilkan limbah seperti limbah industri, limbah domestik dan kegiatan-kegiatan lain yang terjadi di sepanjang daerah aliran sungai (DAS).

Penelitian tentang sebaran kandungan fosfat di muara sungai Bodri ini memiliki tujuan untuk mengetahui kandungan fosfat di lokasi tersebut, dan apabila konsentrasinya melebihi batas aman perairan maka dapat dilakukan monitoring kondisi muara sungai Bodri agar tetap terjaga keseimbangannya dan tidak merugikan bagi biota maupun masyarakat sekitarnya dengan cara meminimalisir pembuangan limbah rumah tangga atau limbas dari limbah masyarakat ke sungai untuk menekan dampak negatif yang berujung pada menjadikan daerah perairan muara sungai Bodri menjadi toksik.. Selain itu tujuan dari penelitian ini adalah untuk mengetahui kandungan serta pola sebaran fosfat di muara sungai Bodri, Kendal.

Pengambilan sampel di Muara Sungai Bodri, Kendal dilaksanakan pada Tanggal 30 September 2020 Lokasi penelitian memiliki batasan area pada koordinat 06 $49^{\prime} 40.46^{\prime \prime}$ - 06 $49^{\prime} 51.42$ " Lintang Selatan dan $110^{\circ} 10^{\prime} 13.86^{\prime \prime}-110^{\circ} 10^{\prime} 23.541^{\prime \prime}$ Bujur Timur. Penentuan lokasi titik penelitian menggunakan metode pertimbangan (purposive sampling dan metode deskriptif. Data yang digunakan dalam menganalisa permasalahan ini adalah data lapangan meliputi data konsentrasi fosfat yang sampelnya diambil dibeberapa titik di Sungai Jajar, kemudian data sekunder meliputi data bathimetri, peta RBI dan data kecepatan serta arah arus di Sungai Bodri yang diperoleh dari pengolahan menggunakan MIKE 21. Selanjutnya data fosfat diolah di laboratorium Kimia dengan metode secara asam askorbat, Fakultas Perikanan dan Ilmu Kelautan, Universitas Diponogoro.

\section{MATERI DAN METODE PENELITIAN}

\section{a. Materi Penelitian}

Materi yang digunakan pada penelitian ini meliputi data primer dan data sekunder. Data primer adalah data utama dalam penelitian ini yaitu konsentrasi fosfat di perairan sungai Bodri, Kendal. Sedangkan data sekundernya adalah data pendukung yang terdiri dari data arus, bathimetri dan peta RBI.

\section{b. Metode Penelitian} penelitian

Penelitian ini menggunakan metode yang bersifat deskriptif. Metode deskriptif adalah metode yang berfungsi untuk memberikan gambaran terhadap objek yang diteliti melalui data atau sampel yang telah terkumpul sebagaimana adanya tanpa melakukan analisis dan kesimpulan yang berlaku untuk umum (Sugiyono, 2009). 


\section{Metode Penentuan Lokasi}

Penentuan lokasi titik penelitian menggunakan metode pertimbangan (purposive sampling) yaitu menentukan lokasi pengambilan sampel berdasarkan pertimbangan-pertimbangan tertentu berdasarkan tujuan dan sasaran penelitian (Sugiyono, 2009), pengambilan sampel ini dilakukan di Muara Sungai Bodri di Kabupaten Kendal yang dilakukan di 9 titik yang berbeda dengan jarak kurang lebih antar titik sekitar 100 meter.

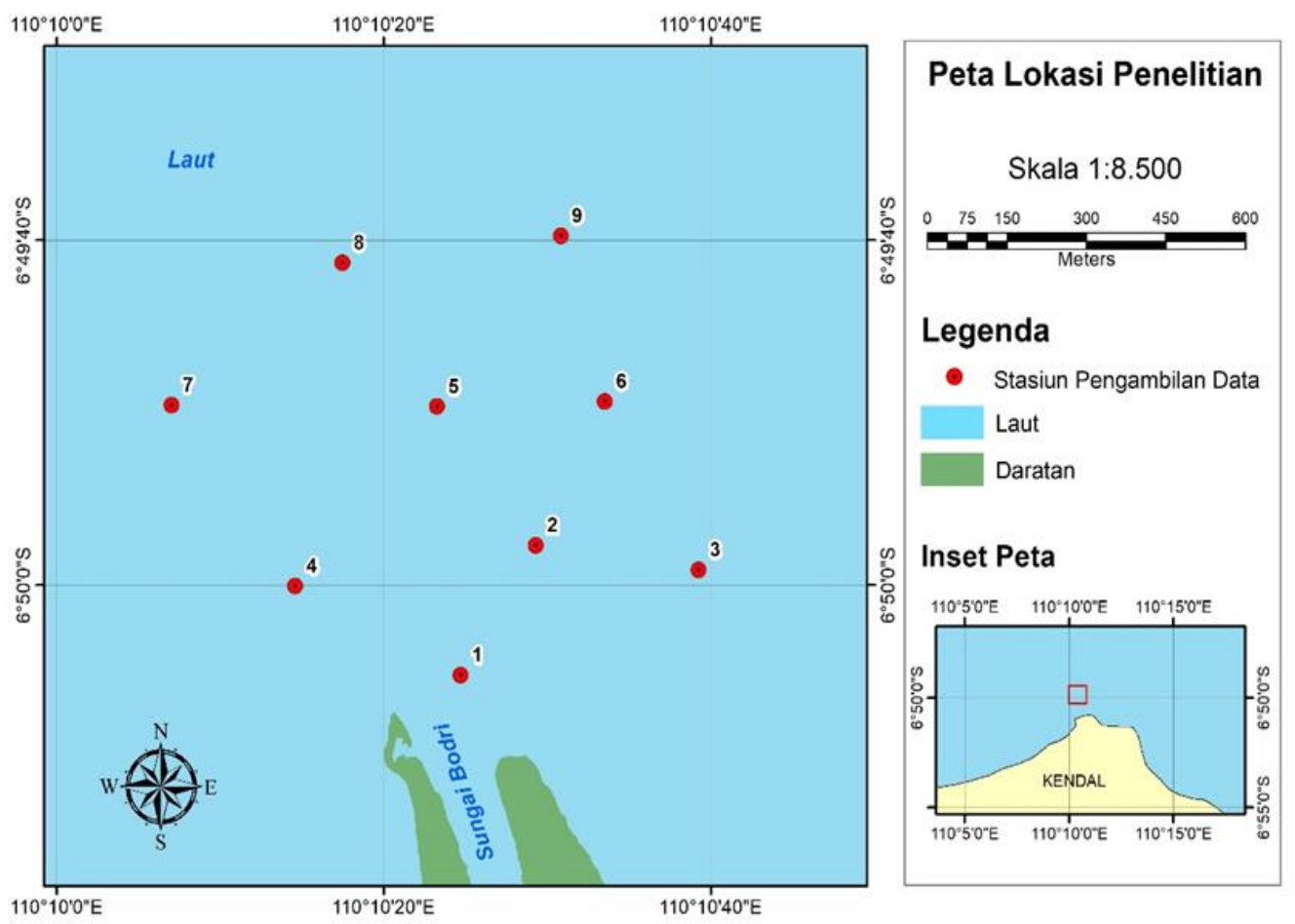

Gambar 1. Peta Lokasi Penelitian

\section{Metode Pengambilan Sampel Air}

Metode pengambilan sampel air permukaan dilakukan pada tanggal 30 September 2020 dengan menggunakan alat yaitu botol Nansen. Botol Nansen sebelum diturunkan ke laut harus dalam keadaan terbuka, setelah turun tepat di permukaan air besi di tali harus diturunkan agar tutup botol dapat tertutup otomatis. Sampel air yang sudah didapatkan di dalam botol Nansen langsung dipindahkan ke dalam botol sampel berukuran 1L dan di simpan ke dalam cool box yang telah diisi dengan es balok untuk menjaga sampel agar tidak rusak

\section{Metode Analisis Data Metode Analisis Fosfat}

Metode analisa sampel fosfat ini didasarkan pada metode SNI 06-6989.31-2005 yaitu cara uji kadar fosfat dengan spektrofotometer secara asam askorbat dan nilainya dinyatakan dalam $\mu \mathrm{M}$. Pada metode ini digunakan larutan dengan konsentasi sebesar $30 \mu \mathrm{mol}$. Selanjutnya larutan standar diencerkan menjadi lima larutan dengan konsentrasi masing-masing sebesar 0,25 $\mu \mathrm{mol}, 0,5 \mu \mathrm{mol}, 0,75 \mu \mathrm{mol}, 1 \mu \mathrm{mol}, 1,25 \mu \mathrm{mol}$. Selanjutnya pembuatan mix reagen amonium molybdate, asam sulfat atau $\mathrm{H} 2 \mathrm{SO} 4$, asam askorbit dan pottasium antimonil tatrat sesuai dengan metode SNI dilakukan dengan perbandingan 2:5:2:1. 


\section{Metode Pengolahan Data Arus}

Data yang digunakan sebagai input dalam simulasi ini adalah peta batimetri dan data arus pasang surut yang telah di ramalkan dari Software MIKE 21. Data arus yang ditetapkan di ambil dari tanggal 15 September 2020 sampai tanggal 15 oktober 2020. Setiap data yang telah dikumpulkan selanjutnya diolah dengan Software DHI MIKE 21. Modul yang digunakan dalam pembuatan model hidrodinamika yaitu modul FlowModel FM dengan waktu simulasi disesuaikan dengan waktu pengambilan sampel lapangan. Aplikasi ini menghasilkan output kecepatan arus pasang surut dan arah arus pasang surut sesuai dengan waktu simulasi yang telah ditetapkan. Output yang telah di dapatkan dari software MIKE 21 tersebut selanjutnya diolah lagi di Software ArcGIS untuk menghasilkan peta sebaran arus.

\section{Metode Pengolahan Peta Sebaran Fosfat}

Pembuatan peta lokasi penelitian dari peta Google Earth wilayah Kendal yang telah disesuaikan dan digitasi dalam software ArcMAP 10.3. Data koordinat stasiun pengambilan sampel dan nilai konsentrasi fosfat yang telah dikonversikan dari nilai absorbansinnya disajikan dalam tabel software Microsoft Excel kemudian diinterpolasi ke dalam ArcMAP 10.3 untuk mengetahui sebaran nilai konsentrasi fosfat di lokasi peneelitian yang telah di tentukan. Pengolahan peta sebaran konsentrasi fosfat ini menggunakan interpolasi Inverse Distance Weight (IDW) yang dilakukan dengan menghubungkan titik - titik pada setiap stasiun yang selanjutnya akan divisualisasikan dengan perubahan tingkat warna. Warna yang gelap akan menunjukan konsentrasi fosfat yang rendah, sedangkan warna yang terang akan menggambarkan konsentrasi fosfat yang tinggi. Metode IDW ini dapat digunakan untuk menaksir suatu nilai pada lokasi yang tidak tersampel berdasarkan data disekitarnya, dalam proses perhitungannya lebih sederhana dan mudah dipahami (Purnomo, 2018).

\section{Metode Pengolahan Peta Arus Laut}

Data arus yang akan diolah diperoleh dari peramalan arus dalam software MIKE 21 pada 15 september 2020 hingga 15 oktober 2020. Setelah diperoleh pemodelan arus pasang surut menggunakan software MIKE 21 kemudian diolah dalam bentuk peta sebaran arus dengan menggunakan software ArcMAP 10.3. Peta tersebut akan menggambarkan bagaiman pola arus yang terjadi pada waktu yang telah di tentukan. Data sebaran arus permukaan kemudian dianalisis terhadap data sebaran fosfat yang didapat dan pola pergerakan arus pasang surut apakah memiliki pengaruh yang signifikan terhadap pola sebaran konsentrasi fosfat di perairan tersebut.

\section{Overlay Peta Sebaran Fosfat dan Peta Sebaran Arus}

Hasil output pemodelan arus pasut yang telah didapat di ekspor nilai kecepatan dan arah arusnya kedalam MS excel agar dapat di Input ke dalam ArcMap 10.3 dan menampilkan pola arus yang telah di modelkan sebelumnya. Langkah yang selanjutnya di lakukan yaitu meng-input data sebaran fosfat yang sebelumnya juga telah di dapatkan. Data SHP daerah Kendal kemudian di input untuk mendapatkan hasil yang di inginkan lalu di lay out sesuai dengan kebutuhan.

\section{HASIL DAN PEMBAHASAN}

Nilai konsentrasi fosfat pada muara sungai Bodri berkisar antara $0.2602-0.3090 \mu \mathrm{M}$ dengan ratarata nilai konsentrasi fosfat sebesar $0.2798 \mu \mathrm{M}$. Nilai fosfat cukup tinggi ditunjukan pada stasiun 1 sampai 3 sedangkan yang tertinggi berada pada stasiun 2. Konsentrasi pada stasiun 4 sampai 9 menunjukan hasil yang linier yang semakin jauh titiknya maka nilai nya semakin naik pula. Hasil pengukuran nilai konsentrasi fosfat tercantum pada Tabel 1, sedangkan peta sebaran fosfat dapat dilihat pada Gambar 2. 
Tabel 1. Hasil Konsentrasi Fosfat ( $\mu \mathrm{M})$ di Muara Sungai Bodri, Kendal

\begin{tabular}{lcc}
\hline No & Stasiun & Konsentrasi \\
\hline 1 & 1 & 0.2827 \\
2 & 2 & 0.3091 \\
3 & 3 & 0.2781 \\
4 & 4 & 0.2602 \\
5 & 5 & 0.2680 \\
6 & 6 & 0.2711 \\
7 & 7 & 0.2804 \\
8 & 8 & 0.2843 \\
9 & 9 & 0.2851 \\
\hline
\end{tabular}
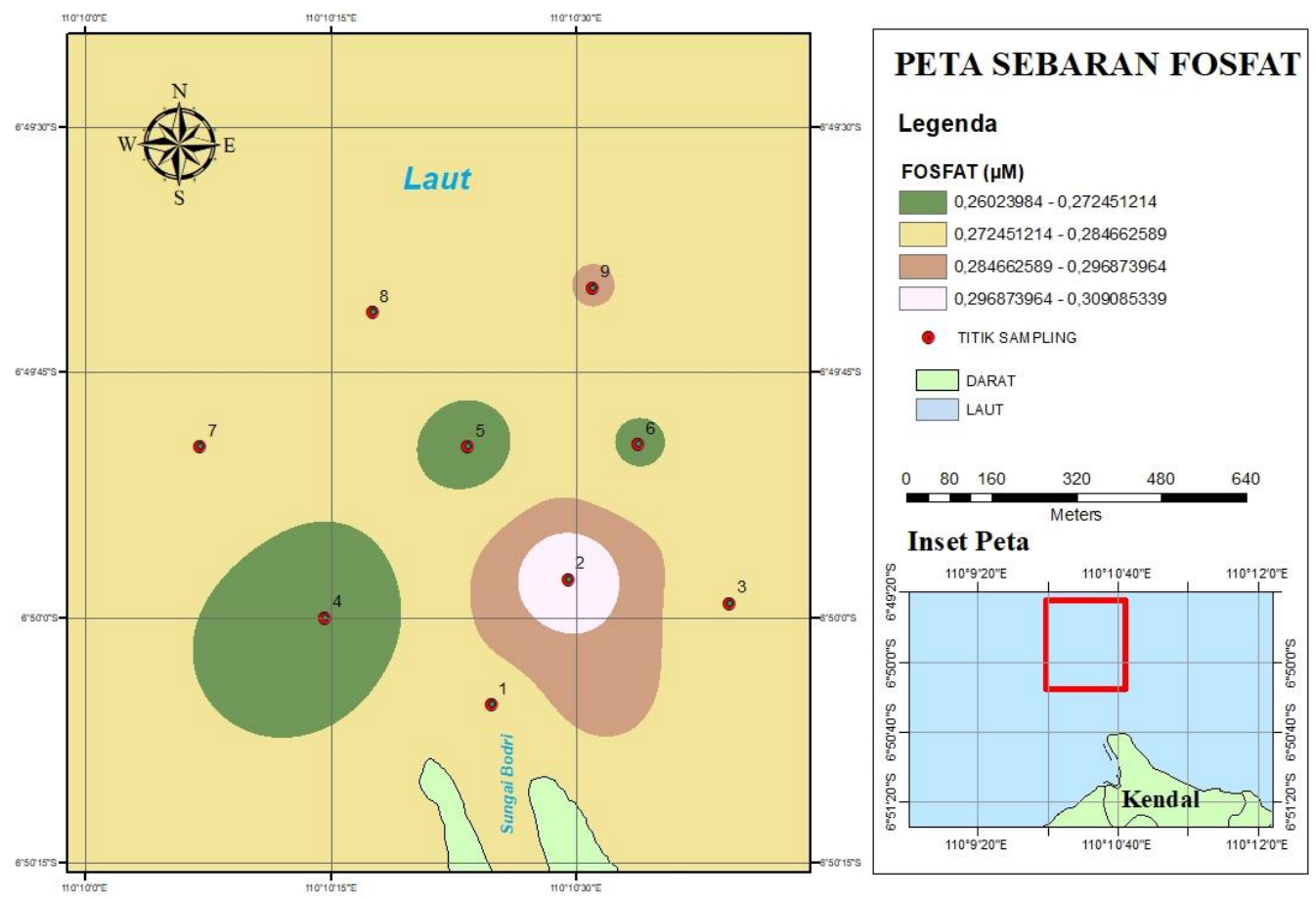

Gambar 2. Peta Sebaran Fosfat di Muara Sungai Bodri, Kendal (Pengolahan Data, 2020)

\section{Arus Pasang Surut}

Hasil simulasi pemodelan arus pasang surut di muara sungai Bodri, Kendal menggunakan software Mike 21 dilakukan dengan waktu simulasi selama 1 bulan, yaitu dari pertengahan bulan September tanggal 15 hingga pertengahan Oktober tanggal 15 tahun 2020. Pola pergerakan arus dominan menuju arah timur laut. Kecepatan arus pada tanggal 30 september 2020 bernilai sebesar 0,000025 - 0,058 m/dtk. Kecepatan arus yang dihasilkan dari pemodelan arus pasang surut menunjukan hasil yang konstan. Hasil pemodelan arus disajikan dalam bentuk peta sebaran arus dan peta sebaran fosfat dengan arus pasang surut disajikan pada Gambar 3 dan 4. 

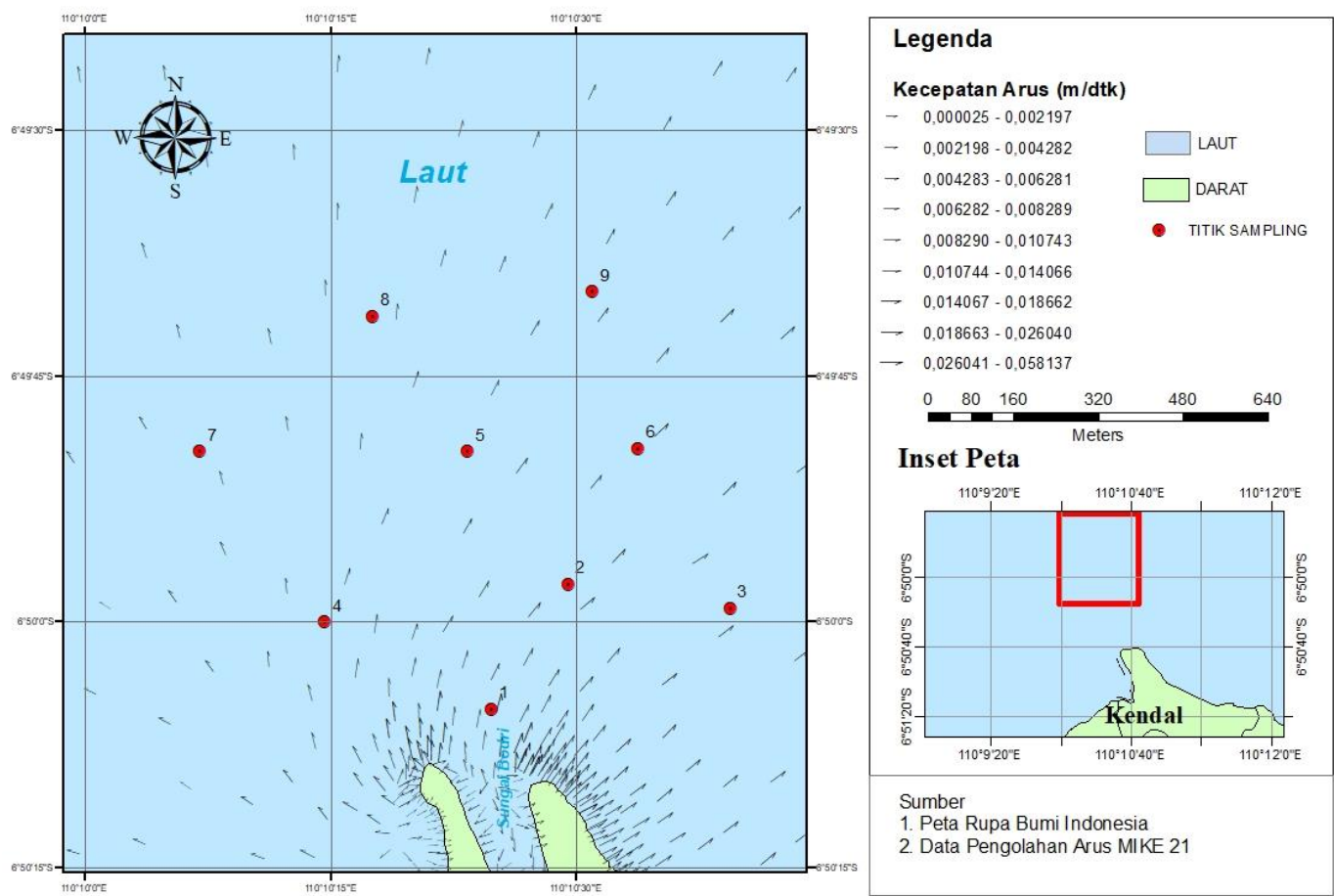

Gambar 3. Peta Sebaran Arus (Pengolahan Data, 2020)

\section{Peta Sebaran Fosfat dan Arus Pasang Surut}

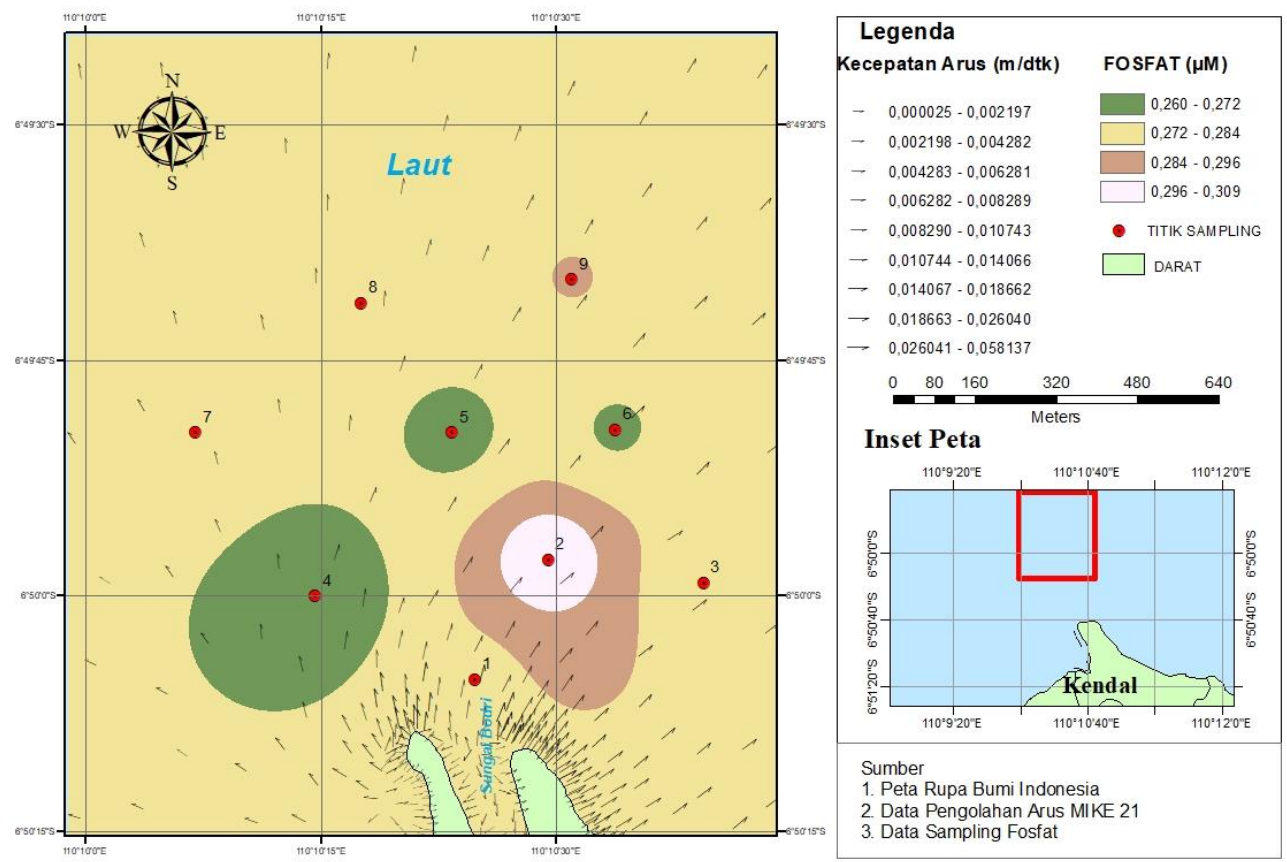

Gambar 4. Peta Sebaran Fosfat dan Arus Pasang Surut (Pengolahan Data, 2020) 
Hasil overlay peta sebaran fosfat dengan arus pasang surut di Muara Sungai Bodri, Kendal menunjukan hubungan yang linier dimana semakin tinggi nilai fosfat maka nilai arus di sekitar titik tersebut juga bernilai tinggi. Pada titik 4,5 dan 6 nilai fosfatnya rendah sehingga besar arus di sekitar titik tersebut juga kecil terlihat dari visual vektor arusnya yang pendek, sedangkan nilai fosfat terbesar berada di titik 2 dan visual vektor arusnya menunjukan vektor panjang dimana yang artinya nilai arus di daerah tersebut juga bernilai besar.

\section{Pembahasan}

Berdasarkan hasil pengamatan, kecepatan arus pada muara sungai Bodri berkisar antara 0,000025 $0,058 \mathrm{~m} / \mathrm{dtk}$. Nilai tertinggi didapatkan pada stasiun 2 yang terletak dekat dengan muara sungai Bodri. Hal tersebut pun juga mempengaruhi nilai dari konsentrasi fosfat di titik tersebut. Menurut Harahap dalam Ihsan (2009), kecepatan arus dapat dibedakan dalam 4 kategori yakni kecepatan arus $0-0,25 \mathrm{~m} / \mathrm{dtk}$ yang disebut arus lambat, kecepatan arus 0,25 - 0,50 m/dtk yang disebut arus sedang, kecepatan arus 0,5 - 1 $\mathrm{m} / \mathrm{dtk}$ yang disebut arus cepat dan kecepatan arus diatas $1 \mathrm{~m} / \mathrm{dtk}$ yang disebut arus sangat cepat. Berdasarkan hasil tersebut disimpulkan bahwa keadaan arus selama penelitian di muara sungai Bodri termasuk ke dalam arus lambat.

Nilai konsentrasi yang didapatkan dari hasil penelitian dan analisa laboratorium menunjukan nilai yang tinggi di stasiun 1,2 dan 3. Kemudian pada titik 4,5,6 menunjukan penurunan nilai konsentrasi yang rendah dan menunjukan sedikit kenaikan di stasiun 7,8 dan 9. Nilai konsentrasi tersebut dipengaruhi oleh banyak faktor baik alam maupun non alam. Faktor alam yang mempengaruhi nilai konsentrasinya adalah arus yang melalui daerah tersebut. Adapun faktor non-alam yang mempengaruhi nilai fosfatnya adalah aktivitas manusia yang ada di sekitar Muara Sungai Bodri seperti kegiatan industri dan buangan limbah.

Berdasarkan hasil penelitian yang telah dilakukan, hasil konsentrasi fosfat di perairan muara sungai Bodri, Kendal berkisar antara 0,2602-0,3090 $\mu \mathrm{M}$ dengan rata-rata nilai konsentrasi fosfat sebesar 0,2798 $\mu \mathrm{M}$ (Tabel 1). Nilai fosfat tertinggi memusat di stasiun 2 yang letaknya berada dekat dengan Muara Sungai Bodri. Nilai kandungan yang tinggi diduga akibat dari hasil aktivitas manusia seperti pembuangan limbah rumah tangga, limbah industri, pertambakan dan tempat pelelangan ikan. Konsentrasi fosfat yang tinggi di muara sungai Bodri sesuai dengan pernyataan Utami et al. (2016) menyatakan, bahwa ting ginya konsentrasi fosfat pada suatu perairan berkaitan dengan adanya pergerakan arus. Arah pergerakan arus di lokasi ini menuju ke arah timur laut dimana pada peta menunjukan bahwa nilai konsentrasi fosfat tinggi di titik 2 dimana titik ini searah dengan pola pergerakan arus. Arus laut memiliki peranan penting dalam proses penyebaran fosfat karena arus laut membawa partikel massa air dari satu tempat ke tempat yang lain.

Nilai kandungan fosfat terendah berada pada titik 4 dikarenakan pada titik ini berada jauh dari muara sungai Bodri dan massa air dari daratan yang menuju laut lepas serta membawa nutrien fosfat tidak melewati titik ini. Tidak adanya masukan nutrien dari dari daratan secara langsung juga mempengaruhi rendahnya nilai konsentrasi fosfat di titik 4. Hubungan nilai konsentrasi fosfat dengan stasiun dapat diketahui bahwa pada stasiun dengan pola sejajar dengan daratan yaitu 1,2,3 kemudian 4,5,6 dan 7,8,9 nilai konsentrasinya dipengaruhi oleh arus yang membawa massa air dari darat mengarah ke timur laut. Adapun stasiun dengan pola 1,4,7 kemudian 2,5,8 dan 3,6,9 konsentrasi fosfatnya dipengaruhi oleh kedalaman perairan dimana stasiun dengan kedalaman terdangkal besar konsentrasi fosfatnya tinggi berangsur turun di kedalaman yang tinggi namun kembali naik konsentrasi fosfatnya di kedalaman paling tinggi.

Penyebaran konsentrasi fosfat di lokasi penelitian bisa dikatakan hampir tidak merata, seperti pada titik 1,2 dan 3 fosfatnya tinggi disebabkan oleh masukan nutrien dari daratan, terutama di titik 2 tinggi karena kandungan fosfat telah terbawa arus yang menyebar dari titik 1 dan menumpuk di titik tersebut. Titik 4 dan 5 memiliki konsentrasi yang rendah karena lokasinya yang menjauhi daratan dan minim terpengaruh oleh arus pasang surut. Nilai konsentrasi pada titik 7,8 dan 9 nilainya sedikit naik namun tidak begitu signifikan, hal ini bisa diakibatkan karena pengaruh kandungan fosfat yang terbawa arus dari stasiun 
sebelumnya.

Gambar peta overlay antara arus dan konsentrasi fosfat menunjukan bahwa pada titik-titik yang memang memiliki konsentrasi tinggi, nilai kecepatan arusnya juga tinggi yaitu berada di rentang 0,01 $0,05 \mathrm{~m} / \mathrm{dtk}$. Hal tersebut dapat dilihat pula dari panjang pendek nya vektor yang di sajikan dalam peta tersebut. Semakin pendek vektor maka nilai arusnya semakin kecil dan semakin panjang vektor maka nilai arusnya semakin besar. Titik 2 dan 9 adalah titik dimana nilai kecepatan arusnya paling tinggi. Nilai kecepatan arus di titik yang konsentrasi fosfat nya rendah berada di rentang 0,008 - 0,01 m/dtk, bahwa nilai kecepatan arus dan nilai konsentrasi fosfat di wilayah penelitian tersebut berbanding lurus.

\section{KESIMPULAN}

Nilai konsentrasi fosfat yang terdapat di perairan muara Sungai Bodri termasuk dalam kategori tinggi, persebaran fosfat secara horizontal yang bernilai tinggi pada perairan yang terletak dekat dengan daratan (muara) kemudian bertahap berkurang menuju arah laut terbuka namun sedikit mengalami peningkatan di titik paling jauh dikarenakan arus yang mengarah ke timur laut.. Persebaran konsentrasi fosfat berbentuk konvergen atau mengelilingi stasiun pengamatan yang terkait dengan pergerakan arus

\section{DAFTAR PUSTAKA}

Cervetto, G., C. Mesones, \& D. Calliari. 2002. Phytoplankton Biomass and its Relationship to Environmental

Variables in a Disturbed Coastal Area of The Rio De La Plata Uruguay, before the New Sewage Collector System. Atlantica, 24(1): 45-54 Hlm.

Falkowski., P. G., 2003. Biogeochemistry of Primary Production in the Sea. Rutgers University, New

Brunswick, NJ, USA. Elsevier Ltd. ISBN (set): 0-08-043751-6 ; (ISBN: 0-08-044343-5); 8: 185-213 Hlm

Harahap, Syawaludin. 2012. Aplikasi Sistem Informasi Geografis (SIG) untuk Zonasi Jalur Penangkapan Ikan di Perairan Kalimantan Barat. Jurnal Akuatika. 3(6) : 40-48. Universitas Padjajaran. ISSN : $0853-2523$

Maslukah. 2015. Sebaran Konsentrasi Nitrat Dan Fosfat Di Perairan Muara Sungai Banjir Kanal Barat,

Semarang. Jurnal Oseanografi. 4(1) ; 85 - 92 Hlm.

Maslukah, L., S. Y. Wulandari., I. B. Prasetyawan \& M. Zainuri. 2019. Distributions and Fluxes of Nitrogen and Phosphorus Nutrients in Porewater Sediments in the Estuary of Jepara Indonesia. Journal of Ecological Engineering. 20(2) : 1-14 Hlm.

Patty, S. I. (2015). Karakteristik Fosfat, Nitrat dan Oksigen Terlarut di Perairan Selat Lembeh, Sulawesi Utara. Jurnal Pesisir dan Laut Tropis. 3(2) : 1-7.

Purnomo, H. 2018. Aplikasi Metode Interpolasi Inverse Distance Weighting Dalam Penaksiran Sumberdaya Literit Nikel (Studi kasus di Blok R, Kabupaten Konawe-Sulawesi Tenggara). Jurnal Ilmiah Bidang Teknologi, Angkasa. 10(1):49-60 Hlm.

Sugiyono. 2009. Metode Penelitian Pendidikan Pendekatan Kuantitatif, Kualitatif, dan R \& D. Bandung : Alfabeta. $380 \mathrm{Hlm}$.

Sutamihardja, R.T.M. 1992. Pencemaran Air Terhadap Pertanian, Perikanan dan Kehidupan Akuatik. Bandung. 29 - $38 \mathrm{Hlm}$.

Utami, T. M. R., L. Maslukah \& M. Yusuf. 2016. Sebaran Nitrat (NO3) dan Fosfat(PO4) di Perairan Karangsong Kabupaten Indramayu. Buletin Oseanografi Marina, 5(1) ; 31 - 37 Hlm. 